\title{
Personal Disaster and Pandemic Preparedness of U.S. Human Resource Professionals
}

\author{
Terri Rebmann ${ }^{1 *}$, Amy M Strawn ${ }^{1}$, Zachary Swick ${ }^{1}$ and David Reddick ${ }^{2}$
}

${ }^{1}$ Institute for Biosecurity, Saint Louis University, College for Public Health and Social Justice, St Louis, MO, USA

${ }^{2}$ Bio-Defense Network, 116 Embassy Lane, Kirkwood, USA

\begin{abstract}
Background: All citizens need to have a personal disaster plan, but past studies indicate poor preparedness. Predictors of preparedness need to be clearly defined so interventions can be developed.

Methods: Human resource (HR) professionals were sent an online survey in May-July, 2011 that assessed their personal/family disaster plan for natural disasters and pandemics, determinants of preparedness, and attitudes and beliefs regarding disaster preparedness. Linear regressions were used to describe factors associated with higher preparedness scores. Chi squares compared attitudes and beliefs about preparedness by whether or not their employer encouraged them to have a personal plan.

Results: $471 \mathrm{HR}$ professionals from 33 states participated. Average scores for personal and pandemic preparedness were 12.6 ( 0 - 20 range) and 4.5 (0- 9 range), respectively.

One-third $(35.3 \%, n=100)$ had half or fewer preparedness measures, and half $(47 \%, n=133)$ had 4 or fewer of the 9 possible pandemic preparedness measures. Determinants of personal preparedness included high perception of personal preparedness for natural disasters and pandemics, having fewer years of work experience, being encouraged by the employer to have a personal preparedness plan, having received disaster preparedness training during the past two years, and not having children in the household. From linear regression, determinants of pandemic preparedness were high perception of personal preparedness for both natural disasters and pandemics, not having children in the household, being male, and having received disaster preparedness training during the past two years. HR professionals whose employer encouraged him/her to have a personal disaster plan had significantly higher perceived importance for family and business preparedness, and higher perceived preparedness compared to those whose employers have not encouraged them to have a personal plan $(p<.001$ for all)
\end{abstract}

Conclusion: HR professionals will play a critical role during a disaster, but many lack personal preparedness.

Keywords: Personal preparedness; Disaster planning; Pandemic; Influenza; Preparedness; Disaster; Plan

\section{Introduction}

Every year, disasters victimize millions of individuals, kill thousands worldwide, and cost billions of dollars [1]. Disaster preparedness can mitigate many of the negative consequences from disasters [2]. Disaster preparedness is essential for all organizations, agencies, and businesses [3], and is also vital for individuals and families or household members [4]. Although regional and federal resources will be made available following a declared public health emergency, deploying these resources will take time. Individuals and/or family/household members may need to be self-sufficient for up to 72 hours before supplies and provisions are made available within communities [5]. Individual/family/household preparedness (hereafter referred to as personal preparedness) is therefore essential to ensure the safety and health of individuals and families. Many organizations and federal agencies have released checklists and guidelines for developing a personal disaster plan for individuals and families/household members [4-7]. Personal disaster plans generally call for both creating stockpiles of tangible supplies, such as nonperishable food and water, as well as designing plans/procedures for emergency response, such as for evacuation and having a designated meeting place for family members who may be separated as a result of the disaster [8].

Many researchers have stated that it is essential that healthcare, public health, and emergency responders have a personal disaster plan so that they are able to continue working during and after a disaster strikes their community, while ensuring the safety of their family members [9-
14]. As a way of better ensuring that such plans are made, it has been suggested that healthcare agency administrators should encourage personnel to have a personal disaster plan [9], that this policy should be implemented on a systems basis [12], and that staff should be told about the policy upon being hired and then annually after that Despite this, multiple studies indicate that the majority of healthcare and public health personnel do not have adequate personal disaster plans $[11,14$ 16]. A study of Missouri nurses found that $75 \%$ did not have at least half of the assessed disaster plan supplies, and $20 \%$ did not have any components of a personal disaster plan [16]. Infection prevention (IPs) professionals, many of whom are often on hospital disaster planning committees and involved in hospital disaster planning activities, were found to be similarly unprepared for a disaster; a 2007 study reported that about half of participating IPs did not have a personal disaster plan [15]. Researchers assessing personal preparedness of public health

*Corresponding author: Terri Rebmann, Institute for Biosecurity, College for Public Health \& Social Justice Saint Louis University, 3545 Lafayette Avenue Room 463, Saint Louis, Missouri 63104, USA, Tel: (314) 977-8260; Fax: (314) 977-8150; E-mail: rebmannt@slu.edu

Received May 21, 2013; Accepted July 06, 2013; Published July 08, 2013

Citation: Rebmann T, Strawn AM, Swick Z, Reddick D (2013) Personal Disaster and Pandemic Preparedness of U.S. Human Resource Professionals. J Biosafety Health Educ 1: 102. doi:10.4172/2332-0893.1000102

Copyright: @ 2013 Rebmann T, et al. This is an open-access article distributed under the terms of the Creative Commons Attribution License, which permits unrestricted use, distribution, and reproduction in any medium, provided the original author and source are credited. 
professionals found that $75 \%$ were minimally to not at all prepared in terms of having a personal disaster plan [14].

Similar findings have been identified in studies examining the personal preparedness of members of the general public [17-21]. A 2004 study from Los Angeles, CA reported that only $28 \%$ of individuals had stockpiled emergency supplies in preparation for a disaster [17]. A more recent study in 2006 found that while only $45 \%$ of the surveyed individuals met objective criteria for being prepared for a disaster, 78\% reported that they believed that they were well prepared for such an event [18]. Researchers examining the factors that influence individuals to create a personal disaster plan have reported a number of predictors of better preparedness, including perceived preparedness [18]. However, the data regarding some predictor variables, such as race, is conflicting. One study reported that African Americans, Latinos, and Asian individuals were better prepared than whites [17], while another found the exact opposite [18]. Three studies have found that individuals with disabilities are more likely to have stockpiled supplies or have an evacuation plan compared to those without disabilities, while two other studies reported that those with disabilities are less likely to be prepared for disasters [17-21]. Although a study of public health professionals reported that risk perceptions of a disaster were not associated with better preparedness [14], a study of the general public found that those with higher risk perceptions of a terrorist attack were more likely to have a personal disaster plan than those with lower risk perceptions [17]. These conflicting findings regarding predictors of personal preparedness and the fact that the most recent study to examine personal preparedness was conducted using 2008 data indicate that more research needs to be done in this area. In addition, no study has examined personal preparedness related to biological events, such as bioterrorism, outbreaks of emerging infectious diseases, or pandemics. Biological disasters are longer-lasting than traditional terrorism or natural disasters and require an increase in supplies that need to be stockpiled (up to 2-3 weeks' worth) [7]. The purposes of this study are to examine the extent to which human resource (HR) professionals have a personal/family disaster plan for natural disasters and pandemics, and to describe the determinants of better preparedness. A secondary aim of the study is to describe HR professionals' attitudes and beliefs regarding disaster preparedness for natural disasters and biological disasters.

\section{Methods}

This study was part of a larger study that examined business continuity for biological events and U.S. businesses' experiences during the $2009 \mathrm{H} 1 \mathrm{~N} 1$ pandemic; the results from that study have been described previously $[5,22]$. The sample consisted of HR professionals who were members of the Society for Human Resource Management (SHRM) organization and who worked for U.S. businesses in June August, 2011. The survey was administrated through Qualtrics, an online research software program. Subjects were recruited through websites of state SHRM organizations, announcement at local SHRM meetings, or through SHRM newsletters. After completing the business continuity study, participants were asked if they would be willing to complete a second survey regarding their personal preparedness. If they agreed, they were directed to a second online survey administrated through Qualtrics. The Saint Louis University Institutional Review Board approved this study.

\section{Instrument}

The instrument was based on existing studies examining personal preparedness as well as planning guides developed by governmental agencies $[7,17,18,23]$. Attitude and belief questions were based on questionnaires used in previous bioterrorism and/or pandemic research studies [16,24-26]. The 40 -item survey consisted of 24 objective items measuring personal preparedness for a natural disaster or biological event, 2 assessing perceived personal preparedness, 5 measuring perceived importance of disaster planning, 4 questions related to risk perceptions for natural disasters and pandemics, 2 focused on perceived interest in disaster planning, and a single question related to disaster training sessions attended in the past two years, perceived cost barriers to personal disaster planning, and administrative encouragement to develop a personal disaster plan. In addition, participant demographics were assessed. A group of 10 U.S. business continuity and pandemic preparedness researchers provided feedback on content validity. A content validity index (CVI) was computed for each item [27]; no items had a CVI below 0.80 , so no items were deleted. The final survey instrument contained 43 questions plus demographic items. Twenty human resources professionals from across the U.S. pilot tested the instrument. Feedback from pilot testing was used to further refine the instrument.

The 24 items that objectively measured personal preparedness were categorical items; most consisted of dichotomous yes or no answer options and were scored 1 or 0 points only. Examples of scoring for these indicators include having at least three days' supply of nonperishable food ( $\geq 3$ days' of stockpiled food: 1 point; less than 3 days' of stockpiled food: 0 points) and having a battery-operated radio with batteries (yes: 1 point; no: 0 points). Some items, such as having at least a 3 days' supply of prescription medication for everyone in the household, included a "not applicable" answer option that was recoded into "yes" (1 point). Survey questions regarding risk perceptions, perceived importance, perceived preparedness, reported interest, and cost barrier to preparedness were measured using a 5-point Likert scale (strongly agree to strongly disagree).

\section{Data Analysis}

The Statistical Package for the Social Sciences $\left(\right.$ SPSS $\left.^{\circledR}\right) 20.0$ was used for all analyses. Descriptive statistics were computed for each question and used to describe personal preparedness of HR professionals and HR professionals' risk perceptions and perceived importance of personal natural disasters and pandemics. A personal preparedness score was calculated by assigning one point for each of 20 possible objective measures of personal preparedness. A pandemic preparedness score was calculated by assigning one point for each of 9 possible objective measures of pandemic preparedness. Five indicators were shared between both personal preparedness and pandemic preparedness (Table 1). The highest possible score for personal preparedness was 20 and 9 for pandemic preparedness (one point for each preparednessspecific indicator).

Chi squares were used to compare HR professionals' attitudes and beliefs about disaster preparedness by whether their employer encouraged them to have a personal disaster plan. McNemar tests were used to compare HR professionals' attitudes and beliefs about disaster preparedness when comparing two attitudinal items, such as their perceived importance of preparing for a natural disaster versus their perceived importance of preparing for a pandemic. Linear regressions were used to describe factors associated with higher personal preparedness and pandemic preparedness scores. Univariate analyses were conducted prior to linear regression analyses, using demographic variables and attitude/belief items, such as age, number of household members, whether their employer encouraged them to have a personal disaster plan, amount of disaster preparedness training received in the 
Table 1: Disaster and pandemic personal preparedness indicators

\begin{tabular}{|c|c|}
\hline Component of Personal Disaster Plan & $\begin{array}{l}\text { Has Plan } \\
\text { Component \% (n) } \\
\mathrm{N}=\mathbf{2 8 3}\end{array}$ \\
\hline Flashlight and batteries & $97.5(276)$ \\
\hline $\begin{array}{l}\text { Non-prescription medication (e.g. pain reliever, fever } \\
\text { reducer) }\end{array}$ & $96.8(270)$ \\
\hline $\begin{array}{l}\geq 3 \text {-days' supply of prescription meds for household } \\
\text { members }\end{array}$ & $95.4(270)$ \\
\hline Smoke detectors on each level of home & $95.1(269)$ \\
\hline Battery-operated radio and batteries* & $83.7(237)$ \\
\hline$\geq 3$-days' supply of non-perishable food for household & $77.9(218)$ \\
\hline Fire extinguisher & $74.2(210)$ \\
\hline $\begin{array}{l}\text { Family members have knowledge of fire extinguisher } \\
\text { use }\end{array}$ & $58.0(164)$ \\
\hline Back-up plan for child/family member care* & $77.4(219)$ \\
\hline Emergency numbers posted near phone/in cell phone & $64.3(182)$ \\
\hline $\begin{array}{l}\text { All members of household familiar with family disaster } \\
\text { plan* }\end{array}$ & $58.7(166)$ \\
\hline Back-up pet care & $56.2(159)$ \\
\hline$\geq$ 3-days' supply of water for household & $54.8(155)$ \\
\hline $\begin{array}{l}\text { Designated safe location for self/family in case of } \\
\text { evacuation }\end{array}$ & $53.7(152)$ \\
\hline $\begin{array}{l}\text { Household members know how to turn off water, gas, and } \\
\text { electricity }\end{array}$ & $47.3(134)$ \\
\hline Out-of-town contact person identified & $44.2(125)$ \\
\hline Medical supplies (e.g. masks, gloves, needles, syringes)* & $43.8(124)$ \\
\hline Sheltering-in-place procedures & $38.2(108)$ \\
\hline Back-up transportation & $34.6(98)$ \\
\hline Household regularly conducts emergency evacuation drills & $8.5(24)$ \\
\hline Disaster Plan Components & $\begin{array}{l}\text { Has Plan Component } \\
\%(\mathrm{~N})\end{array}$ \\
\hline $\begin{array}{l}\text { Non-prescription medication (e.g. pain reliever, fever } \\
\text { reducer) }\end{array}$ & $95.4(270)$ \\
\hline Battery-operated radio and batteries* & $83.7(237)$ \\
\hline Back-up plan for child/family member care* & $77.4(219)$ \\
\hline $\begin{array}{l}\text { All members of household familiar with family disaster } \\
\text { plan* }\end{array}$ & $58.7(166)$ \\
\hline $\begin{array}{l}\geq 14 \text {-days' supply of prescription meds for household } \\
\text { members }\end{array}$ & $53.7(152)$ \\
\hline Medical supplies (e.g. masks, gloves, needles, syringes) ${ }^{*}$ & $43.8(124)$ \\
\hline$\geq 1$ mask/respirator stored & $20.5(58)$ \\
\hline$\geq$ 14-days' supply of non-perishable food for household & $14.8(42)$ \\
\hline$\geq 14$-days' supply of water for household & $3.5(10)$ \\
\hline
\end{tabular}

*Indicator part of both pandemic preparedness and personal preparedness

past two years, risk perceptions, and perceived importance of disaster planning. Only variables that were significant in univariate analysis (with a critical p-value of .05) were included in the multivariate analyses. Variables that were significant on univariate analysis, but non-significant on multivariate analysis were dropped from the model; only final models are reported. A critical p-value of .05 was used for all analyses.

\section{Results}

A total of 283 HR professionals from 24 states participated in the study, representing $60 \%$ of the original sample obtained for the larger business continuity study [5]. The majority of participants were female $(83.4 \%, \mathrm{n}=231)$ and over the age of 30 , with most HR professional being between the ages of $31-40(18.4 \%, n=51), 41-50(37.2 \%, n=103)$, or over $51(36.8 \%, n=102)$. Almost three-quarters of the participating HR professionals $(72.4 \%, \mathrm{n}=205)$ had either a bachelor's $(43.0 \%, \mathrm{n}=119)$ or master's degree $(31.0 \%, \mathrm{n}=86)$. Almost all of the HR professional participants $87 \%(\mathrm{n}=241)$ had significant work experience, with most having either $5-10$ years' $(28.9 \%, n=80)$ or 11 or more years' $(58.1 \%$, $\mathrm{n}=161)$ of HR work experience. They were most likely to live in either the South $(48.0 \%, \mathrm{n}=133)$ or Midwest $(39.0 \%, \mathrm{n}=108)$. The HR professionals reported working in a wide variety of business types, with the most frequently reported employer types including education $(10.2 \%, n=29)$, healthcare $(9.9 \%, n=28)$, or a governmental agency $(13.8 \%, n=39)$. The majority of employers $(77.7 \%, \mathrm{n}=167)$ were for-profit agencies. Almost half of the HR professionals $(46.2 \%, n=128)$ reported being a member of their company's disaster planning committee.

\section{Personal preparedness and personal pandemic preparedness}

The survey contained 20 indicators of personal preparedness and 9 indicators of pandemic preparedness, contributing to a maximum score of 20 and 9 for personal preparedness and pandemic preparedness, respectively. Scores for personal preparedness ranged from $0-20$, with an average score of $12.6(\mathrm{sd}=4.4)$. Approximately one-third of participants $(35.3 \%, n=100)$ had half of fewer of the objective measures of personal preparedness. Pandemic preparedness scores ranged from 0-9, with an average score of $4.5(\mathrm{sd}=1.8)$. Almost half of the HR professionals $(47 \%$, $\mathrm{n}=133$ ) reported having 4 or fewer of the 9 possible objective measures of pandemic preparedness. Indicators of personal preparedness and pandemic preparedness, as well as the frequency with HR professionals had each component of preparedness are outlined in Table 1. The most frequently reported indicators of personal preparedness (excluding shared indicators with pandemic preparedness, (Table 1) were having a flashlight and batteries $(97.5 \%, \mathrm{n}=276)$, at least 3-days' supply of prescription medication for each person who takes prescribed medicine in household $(95.4 \%, \mathrm{n}=267)$, and smoke detectors on each level of home $(95.1 \%, n=269$. The least frequently reported indicators of personal preparedness included having procedures for sheltering-inplace for the household $(38.2 \%, \mathrm{n}=108)$, having back-up transportation plans $(34.6 \%, \mathrm{n}=98)$, and conducting regular household emergency evacuation drills $(8.5 \%, \mathrm{n}=24)$. From linear regression, determinants of personal preparedness were as follows: high perception of personal preparedness for both natural disasters and pandemics, having fewer years of work experience, being encouraged by the employer to have a personal preparedness plan, having received disaster preparedness training during the past two years, and not having children in the household (Table 2). Age, gender, race, education level, number of people living in household, having a disabled person living in the household, risk perceptions related to natural disasters or pandemics, perceived importance of or interest in personal preparedness or business continuity of employer, perceived cost of personal planning as a barrier, being a member of their employer's disaster planning committee, type of employing agency (healthcare, retail, food, utilities, etc), size and location (urban, suburban, or rural area) of employing agency were not significant predictors of HR professionals' personal disaster plans.

The most frequently reported indicators of pandemic preparedness (including shared indicators with personal preparedness, (Table 1) were having a supply of non-prescription medication (95.4\%, $\mathrm{n}=270)$, having a battery-operated radio and batteries $(83.7 \%, \mathrm{n}=837)$, and having back-up childcare/eldercare plans $(77.4 \%, \mathrm{n}=219)$. The least frequently reported indicators of pandemic preparedness included having at least one mask or respirator stored $(20.5 \%, \mathrm{n}=58)$, a two-weeks' or longer supply of non-perishable food $(14.8 \%, \mathrm{n}=42)$, and a two-weeks' or longer supply of water stockpiled in the home $(3.5 \%, n=10)$. From linear regression, determinants of pandemic preparedness were as follows: high perception of personal preparedness for both natural 
Citation: Rebmann T, Strawn AM, Swick Z, Reddick D (2013) Personal Disaster and Pandemic Preparedness of U.S. Human Resource Professionals. J Biosafety Health Educ 1: 102. doi:10.4172/2332-0893.1000102

Page 4 of 7

disasters and pandemics, not having children in the household, being male, and having received disaster preparedness training during the past two years (Table 2). Age, education level, years of work experience in human resources, number of people living in household, having a disabled person living in the household, risk perceptions related to natural disasters or pandemics, perceived importance of or interest in personal preparedness or business continuity, perceived cost of personal planning as a barrier, being a member of their employer's disaster planning committee, type of employing agency, size and location of employing agency were not significant predictors of HR professionals' personal disaster plans.

\section{Attitudes and beliefs about disaster preparedness}

Almost all HR professionals reported that preparing for natural disasters is important, with more agreeing that it is important to them that their family be prepared compared to having their employer be prepared $(94.3 \%$ versus $89 \%, \mathrm{p}<.001)$. HR professionals also reported that preparing their family for natural disasters is more important to them than preparing their family for a pandemic (94.3\% versus $80.6 \%, \mathrm{p}<.001)$. Perceived importance of employer preparedness for natural disasters was reported to be higher than perceived importance of company pandemic preparedness ( $89 \%$ versus $80.6 \%, \mathrm{p}<.01)$. HR professionals whose employer encouraged him/her to have a personal disaster plan were significantly more likely to report that disaster planning is important for their family and their employer, that they are interested in disaster planning for family and their employer, and that they are well prepared to face either a natural disaster or pandemic compared to those whose employers have not encouraged them to have a personal plan (Table 3 ).

Almost 70\% (68.2\%, $\mathrm{n}=193)$ HR professionals reported being interested in personal disaster planning; significantly fewer $(54.4 \%$, $\mathrm{n}=154 ; \mathrm{p}<.001)$ reported being interested in business preparedness for disasters. About half $(53.7 \%, n=152)$ reported that they and their family are well prepared to face a natural disaster; significantly fewer $(33.6 \%, \mathrm{n}=95)$ reported that their family is prepared for a pandemic. As mentioned earlier, perceived preparedness was associated with objective

Table 2: Factors related to disaster and pandemic personal preparedness.

\begin{tabular}{|c|c|c|c|c|c|c|}
\hline \multirow[b]{2}{*}{ Factor } & \multicolumn{3}{|c|}{ Disaster Preparedness } & \multicolumn{3}{|c|}{ Pandemic Preparedness } \\
\hline & $\beta$ & S.E. & p value & $\beta$ & S.E. & p value \\
\hline \multicolumn{7}{|l|}{ Perception of personal preparedness } \\
\hline Natural disaster & 3.1 & .48 & $<.001$ & 1.0 & .24 & $<.001$ \\
\hline Pandemic & 1.8 & .51 & $<.001$ & .70 & .25 & $<.01$ \\
\hline \multicolumn{7}{|l|}{ Years working in $\mathrm{HR}^{*}$} \\
\hline $1-2$ years & 3.0 & 1.4 & $<.05$ & NIM & NIM & NIM \\
\hline No children in household & 1.2 & .20 & $<.01$ & .64 & .10 & $=.001$ \\
\hline Employer encouragement to have plan & .92 & .39 & $<.05$ & NIM & NIM & NIM \\
\hline Disaster preparedness training in last two years & .32 & .10 & $=.001$ & .13 & .05 & $<.01$ \\
\hline Gender (male) & NIM & NIM & NIM & .61 & .25 & $<.05$ \\
\hline
\end{tabular}

S.E. = standard error; NIM = Not in Model

*Years' experience referent: $\geq 3$ years

Table 3: Human resource professionals' attitudes and beliefs about disaster preparedness by employer encouragement to have plan.

\begin{tabular}{|c|c|c|c|c|c|c|c|}
\hline \multirow{3}{*}{ Statement } & \multicolumn{2}{|c|}{$\begin{array}{l}\text { All Respondents } \\
\qquad \mathbf{N}=\mathbf{2 8 3}\end{array}$} & \multicolumn{5}{|c|}{ Encouragement to Have a Personal Plan N = 283} \\
\hline & \multirow{2}{*}{$\begin{array}{l}\text { \% That Strongly } \\
\text { Agreed or Agreed }\end{array}$} & \multirow[b]{2}{*}{$\mathbf{n}$} & \multicolumn{2}{|l|}{ Encouraged $\mathrm{N}=$} & \multicolumn{2}{|c|}{ Not Encouraged $\mathbf{N}=$} & \multirow{2}{*}{$\begin{array}{c}\text { Enc. vs. Not Enc } \\
\text { P value* }^{*}\end{array}$} \\
\hline & & & $\begin{array}{l}\text { \% That Strongly } \\
\text { Agreed or Agreed }\end{array}$ & $\mathbf{n}$ & $\begin{array}{l}\text { \% That Strongly } \\
\text { Agreed or Agreed }\end{array}$ & $\mathbf{n}$ & \\
\hline It is important that me/my family be prepared for a natural disaster & 94.3 & 267 & 97.9 & 137 & 90.9 & 130 & $=.01$ \\
\hline It is important that my company be prepared for a natural disaster & 89.0 & 252 & 94.3 & 132 & 83.9 & 120 & $<.01$ \\
\hline It is important that $\mathrm{I} / \mathrm{my}$ family have/has a personal disaster plan & 86.9 & 246 & 94.3 & 132 & 79.7 & 114 & $<.001$ \\
\hline It is important that me/my family be prepared for a pandemic & 80.6 & 228 & 87.9 & 123 & 73.4 & 105 & $<.01$ \\
\hline It is important that my company be prepared for a pandemic & 80.6 & 228 & 86.4 & 121 & 74.8 & 107 & $=.01$ \\
\hline I am interested in personal disaster preparedness & 68.2 & 193 & 75.7 & 106 & 60.8 & 87 & $<.01$ \\
\hline I am interested in business continuity planning & 54.4 & 154 & 65.7 & 92 & 43.4 & 62 & $<.001$ \\
\hline I/my family are well prepared to face a natural disaster & 53.7 & 152 & 70.0 & 98 & 37.8 & 54 & $<.001$ \\
\hline A natural disaster will likely affect my company's business in the next 5 years & 52.7 & 149 & 59.3 & 83 & 46.2 & 66 & $<.05$ \\
\hline I/my family are well prepared to face a pandemic & 33.6 & 95 & 47.9 & 67 & 19.6 & 28 & $<.001$ \\
\hline A natural disaster will likely affect my company's business in the next year & 29.9 & 84 & 42.1 & 59 & 17.5 & 25 & $<.001$ \\
\hline A pandemic will likely affect my company's business in the next 5 years & 20.1 & 57 & 21.4 & 30 & 18.9 & 27 & NS \\
\hline Developing and/or maintaining a personal disaster plan is too expensive & 13.4 & 38 & 12.9 & 18 & 14.0 & 20 & NS \\
\hline A pandemic will likely affect my company's business in the next year & 6.7 & 19 & 12.1 & 17 & 1.4 & 2 & $<.001$ \\
\hline
\end{tabular}

NS $=$ Not significant

*Determined by the $X^{2}$ test 
measures of preparedness for both natural disasters and pandemics (Table 2). Very few HR professionals $(13.4 \%, n=38)$ reported that developing and maintaining a personal disaster plan is too expensive, and there were no differences in this attitude, regardless of whether the employer encourages staff to have a personal disaster plan (Table 3).

\section{Risk perceptions about natural disasters and pandemics}

HR professionals were asked how strongly they agreed or disagreed that a natural disaster or pandemic was likely to affect their employer's business during the next year or next five years. About half of the HR professionals $(52.7 \%, \mathrm{n}=149)$ reported that they believe it is likely that a natural disaster will affect their company's business during the next five years; significantly fewer $(29.9 \%, \mathrm{n}=84 ; \mathrm{p}<.001)$ reported that one will occur in the next year (Table 3 ). Perceived risk of a pandemic was far lower compared to that of a natural disaster ( $\mathrm{p}<.001$ for both), regardless of whether it would occur in the next year or next five years. Only $20 \%(\mathrm{n}=57)$ and $6.7 \%(\mathrm{n}=19)$ reported that they believe it is likely that a pandemic will occur during the next five years or next year, respectively (Table 3). Perceived risk for a pandemic in the next five years was significantly higher than for one occurring during the next year $(\mathrm{p}<.001)$. Risk perceptions related to a natural disaster or a pandemic affecting the employer's company during the next year or five years were significantly lower than perceived importance for preparing the family or the company for such events ( $\mathrm{p}<.001$ for all comparisons).

HR professionals whose employer encouraged him/her to have a personal disaster plan were significantly more likely to report high risk perceptions related to a natural disaster occurring in the next year or five years, or a pandemic occurring in the next five years compared to those whose employers have not encouraged them to have a personal plan (Table 3). There were no significant differences between risk perception related to a pandemic occurring in the next five years and whether the employer encourages staff to have a personal disaster plan (Table 3).

\section{Discussion}

This study examined the personal preparedness of HR professionals across the U.S., including identifying predictors of better personal preparedness. Similar to previously published personal preparedness studies among healthcare personnel and the general public, this study found that, although most HR professionals report that personal disaster preparedness is important to them and their family, many lack adequate personal disaster plans. About a third of the respondents had half or fewer of the objectives measures of preparedness that were assessed. This very low level of preparedness means that many HR professionals would lack the resources and supplies needed during a disaster. Researchers indicate that it is vital that individuals and families have the capability of being self-sufficient for a few days during a large-scale disaster before outside resources may be brought into the community and distributed [18]. It is also important that citizens understand that regional and national stockpiles of supplies will not be adequate to address all communities' needs and that households that have prepared in advance will likely fare better after a disaster occurs. The U.S.s experiences during the $2009 \mathrm{H} 1 \mathrm{~N} 1$ pandemic confirmed that federal resources are inadequate to assist all communities [28], and that event was considered mild compared to the potential for a future pandemic or large-scale disaster [5]. Some researchers have even argued that personal preparedness is a form of social justice, because it allows limited resources to be targeted to the least advantaged members of society, such as those with very low incomes and lack of access to healthcare [12].
It is unclear why so many HR professionals are ill prepared for disasters when the majority of them report that personal preparedness is important to them. Contrary to prior research [17], this study found that risk perceptions of a disaster were not associated with better preparedness. This finding is surprising, given that health promotion theories, such as the Health Belief Model, indicate that perception of risk regarding a negative event or outcome is often associated with choosing to engage in healthy behaviors $[16,29]$. HR professionals in this study had sub-optimal personal preparedness in terms of having adequate supplies stockpiled and developing a personal disaster plan, regardless of the extent to which perceived a natural disaster or pandemic to be a risk in the next five years. Therefore, other influencing factors must exist that help account for the general lack of preparedness found in this study. One hypothesized reason was the cost associated with stockpiling supplies; however, very few HR professionals in this study reported that developing a plan is too expensive and believing that costs were a significant barrier was not a significant predictor of having a personal disaster plan.

The HR professionals in this study reported having a more robust personal plan that addresses natural disasters and traditional terrorism events; their pandemic preparedness plans were far less thorough. Approximately half of the HR professionals had half or fewer of the objective measures of pandemic preparedness. Biological events require different resources compared to those needed during a natural disaster, such personal protective equipment and over-the-counter medications to treat symptoms of infection. In addition, pandemics are prolonged disasters, with each pandemic wave lasting $6-12$ weeks; this means that individuals need to have more supplies stockpiled to get them through the disaster until community services are back to full capacity. The extent to which individuals have a personal disaster plan specific to preparing for a biological event has never been evaluated for any occupation or group of individuals, including the general public. However, two studies have reported that K-12 schools' and businesses' disaster plans are more robust for addressing natural disasters compared to their preparedness for biological events [3,22]. Therefore, the lack of personal disaster plans related to biological events identified in this study is not surprising; it simply reflects the lower preparedness for biological events that exists among U.S. businesses. The reasons why HR professionals reported having less robust pandemic preparedness plans are unclear. Perhaps HR professionals are unaware of why a personal disaster plan is needed for a biological event, or they may not know what should be included in such a plan. Future research studies should attempt to further delineate influencing factors that affect individuals from developing personal preparedness plans for all types of disasters, including biological events [7]. Once the reason(s) for nonparticipation in personal disaster planning have been fully identified, interventions can be developed to address these issues.

Two important predictors for personal preparedness identified in this study include being encouraged by an employer to have a plan and having received disaster preparedness training during the past two years. It would be beneficial to employers to encourage HR professionals to have a personal disaster plan because having such a plan increases the likelihood that staffs are able and willing to work during a disaster [30]. HR professionals will be essential during disaster response because they serve as a source for staffing, training, employee benefits, and employee relations; they will be able to identify and obtain back-up staff during disasters if surge capacity is needed or if personnel are unable or unwilling to work. In addition, HR professionals can help increase company resiliency by encouraging new and existing employees to develop and maintain a personal disaster plan. 
Researchers indicate that a policy indicating that administrators or HR professionals encourage staff to develop a personal disaster plan should be implemented on a systems basis and that personnel should be told about the policy when hired and annually after that; HR professionals could be the individuals that inform staff about this policy and monitor personnel's compliance $[9,12]$. Because recent disaster preparedness training was also associated with better disaster preparedness, it would be beneficial for administrators to encourage staff to participate in disaster planning educational programs or providing such training to employees. Educational programs have been shown to increase staff awareness for the need to better personally prepare for a disaster and to result in higher personal preparedness among emergency department personnel [11].

Similar to previously published studies [16,25], this study found that many HR professionals have low risk perceptions related to natural disasters and biological events. Also similar to previous research [25], this study found that risk perceptions related to natural disasters were higher than perceived risk of a pandemic occurring. Historically, pandemics occur much less frequently than natural disasters and terrorism events. However, pandemics are unpredictable and can occur at any time. For example, the $2009 \mathrm{H} 1 \mathrm{~N} 1$ pandemic was completely unexpected; epidemiologists had predicted that avian influenza H5N1 might mutate and cause a pandemic, yet $\mathrm{H} 1 \mathrm{~N} 1$ occurred seemingly out of nowhere and became a pandemic just two weeks after the first case was identified in the U.S. [31] In addition, other biological events, such as bioterrorism or outbreak of an emerging infectious disease, cause the same response challenges as pandemics, and could occur at any time.

One of the primary strengths of this study is that it is the first to measure individuals' personal preparedness for both natural disasters and biological events. Strength is that it is one of only a few studies to identify predictor variables for personal preparedness; most previous studies have only been descriptive in nature. Some limitations must also be acknowledged. This study involved only HR professionals, and thus is not generalizable to the general public as a whole. In addition, only HR professionals who belong to SHRM were invited to participate; therefore, it may not be generalizable to all HR professionals. There is likely some responder bias in this study, as is common with survey research as a whole. Human resource professionals with an interest in personal disaster planning were likely more willing to participate in this survey, leading to possible bias in the results. This study could not directly assess individual characteristics of the non-responders, and this could potentially limit the generalizability of the findings. Lastly, this study may have some bias related to the finding that having no children was associated with better preparedness. Because participants without children were not penalized for not having an emergency childcare plan (i.e., they were given credit for having that component in their plan), this may have introduced some bias. Future research should examine this issue more closely.

\section{Acknowledgement}

The authors would like to thank Dipti Subramaniam for assisting in instrument development and psychometric testing.

\section{References}

1. Guha-Sapir D, Vos F, Below R., Ponserre S (2012) Annual Disaster Statistical Review: The Numbers and Trends. Brussels: Centre for Research on the Epidemiology of Disasters (CRED).

2. Levac J, Toal-Sullivan D, O'Sullivan TL (2012) Household emergency preparedness: a literature review. J Community Health 37: 725-733.

3. Rebmann T, Elliott MB, Reddick D, D Swick Z (2012) US school/academic institution disaster and pandemic preparedness and seasonal influenza vaccination among school nurses. Am J Infect Control 40: 584-589.

4. Missouri Department of Health and Human Services (2013).

5. Rebmann T, Wang J, Reddick D, Swick Z, Minden-Birkenmaier C (2013) Healthcare versus non-healthcare businesses' experiences during the 2009 H1N1 pandemic: Financial impact, vaccination policies, and control measures implemented. Am J Infect Control 41: e49-54.

6. American Red Cross (2013) Prepare your home and family.

7. Centers for Disease Control and Prevention. Pandemic Flu Planning Checklist for Individuals and Families. 2007.

8. Centers for Disease Control and Prevention (2013) Emergency preparedness and you.

9. Qureshi K, Gershon RR, Sherman MF, Straub T, Gebbie E, et al. (2005) Health care workers' ability and willingness to report to duty during catastrophic disasters. J Urban Health 82: 378-388.

10. Amaratunga CA, O'Sullivan TL, Phillips KP, Lemyre L, O'Connor E, et al. (2007) Ready, aye ready? Support mechanisms for healthcare workers in emergency planning: a critical gap analysis of three hospital emergency plans. Am J Disaster Med 2: 195-210.

11. Bartley BH, Stella JB, Walsh LD (2006) What a disaster?! Assessing utility of simulated disaster exercise and educational process for improving hospital preparedness. Prehosp Disaster Med 21: 249-255.

12. Kass NE, Otto J, O'Brien D, Minson M 2008) M. Ethics and severe pandemic influenza: Maintaining essential functions through a fair and considered response. Biosecur Bioterror 6: 227-236.

13. Fowkes V, Ablah E, Oberle M, Sandrock C, Fleming P (2010) Emergency preparedness education and training for health professionals: a blueprint for future action. Biosecur Bioterror 8: 79-83.

14. Blessman J, Skupski J, Jamil M, Jamil H, Bassett D, et al. (2007) Barriers to at-home-preparedness in public health employees: implications for disaste preparedness training. J Occup Environ Med 49: 318-326.

15. Rebmann T, Wilson R, LaPointe S, Russell B, Moroz D (2009) Hospital infectious disease emergency preparedness: a 2007 survey of infection contro professionals. Am J Infect Control 37: 1-8.

16. Rebmann T, Mohr LB (2008) Missouri nurses' bioterrorism preparedness Biosecur Bioterror 6: 243-251.

17. Eisenman DP, Wold C, Fielding J, Long A, Setodji C, et al. (2006) Differences in individual-level terrorism preparedness in Los Angeles County. Am J Prev Med 30: 1-6.

18. Ablah E, Konda K, Kelley CL (2009) Factors predicting individual emergency preparedness: a multi-state analysis of 2006 BRFSS data. Biosecur Bioterror 7: 317-330.

19. Eisenman DP, Zhou Q, Ong M, Asch S, Glik D, et al. (2009) Variations in disaster preparedness by mental health, perceived general health, and disability status. Disaster Med Public Health Prep 3: 33-41.

20. Smith DL, Notaro SJ (2009) Personal emergency preparedness for people with disabilities from the 2006-2007 Behavioral Risk Factor Surveillance System. Disabil Health J 2: 86-94

21. Uscher-Pines L, Hausman AJ, Powell S, DeMara P, Heake G, et al. (2009) Disaster preparedness of households with special needs in southeastern Pennsylvania. Am J Prev Med 37: 227-230.

22. Rebmann T, Wang J, Swick Z, Reddick D, deIRosario JL Jr (2013) Business continuity and pandemic preparedness: US health care versus non-health care agencies. Am J Infect Control 41: e27-33.

23. Federal Emergency Management Agency (2009) Are You Ready? Emergency Planning and Checklist.

24. Shadel BN, Rebmann T, Clements B, Chen JJ, Evans RG (2003) Infection contro practitioners' perceptions and educational needs regarding bioterrorism: results from a national needs assessment survey. Am J Infect Control. 31: 129-134.

25. Shadel BN, Chen JJ, Newkirk RW, Lawrence SJ, Clements B, et al. (2004) Bioterrorism risk perceptions and educational needs of public health professionals before and after September 11, 2001: a national needs assessment survey. J Public Health Manag Pract 10: 282-289. 
Citation: Rebmann T, Strawn AM, Swick Z, Reddick D (2013) Personal Disaster and Pandemic Preparedness of U.S. Human Resource Professionals. J Biosafety Health Educ 1: 102. doi:10.4172/2332-0893.1000102

26. Rebmann T, Mohr LB (2010) Bioterrorism knowledge and educational participation of nurses in Missouri. J Contin Educ Nurs 41: 67-76.

27. Lynn MR (1986) Determination and quantification of content validity. Nurs Res 35: $382-385$

28. Rebmann T, Wagner W (2009) Infection preventionists' experience during the first months of the 2009 novel H1N1 influenza A pandemic. Am J Infect Control 37: e5-5e16.

29. Janz NK, Champion, VL, Strecher VJ (2008) The Health Belief Model. In: Glanz
K, Rimer, B. K., \& Viswanath, K, ed. Health behavior and health education Theory, research, and practice. 4th ed. San Francisco: Jossey-Bass; 2008: 4566.

30. Goodhue CJ, Burke RV, Ferrer RR, Chokshi NK, Dorey F, et al. (2012) Willingness to respond in a disaster: a pediatric nurse practitioner national survey. J Pediatr Health Care 26: e7-20.

31. Centers for Disease Control and Prevention (CDC) (2009) Swine influenza A (H1N1) infection in two children--Southern California, March-April 2009. MMWR Morb Mortal Wkly Rep 58: 400-402. 